\title{
Temperatura mínima de relva em Santa Maria, RS: climatologia, variabilidade interanual e tendência histórica
}

\author{
Nereu Augusto Streck ( $\left.{ }^{1 *}\right)$; Luana Fernandes Gabriel (3); Arno Bernardo Heldwein (1); \\ Galileo Adeli Buriol (2); Gizelli Moiano de Paula ( $\left.{ }^{3}\right)$ \\ (') Universidade Federal de Santa Maria (UFSM), Departamento de Fitotecnia, Centro de Ciências Rurais, Avenida Roraima, 1000, \\ 97105-900 Santa Maria (RS). \\ (2) Centro Universitário Franciscano (UNIFRA), Rua dos Andradas, 1614, 97010-032 Santa Maria (RS). \\ (3) UFSM, Programa de Pós-Graduação em Agronomia e Engenharia Agrícola, 97105-900 Santa Maria (RS). \\ $\left(^{*}\right)$ Autor correspondente: nstreck2@yahoo.com.br
}

Recebido: 16/jun./2010; Aceito: 17/out./2010

\section{Resumo}

O objetivo do trabalho foi calcular as estatísticas descritivas para caracterizar a climatologia da temperatura mínima de relva, a mínima do ar a $5 \mathrm{~cm}$ do solo coberto com grama (Tmr), em Santa Maria (RS), associar a variabilidade interanual desse parâmetro com o fenômeno ENOS e verificar se há tendência de alteração na série histórica deste elemento meteorológico. Foram usados dados diários de temperatura mínima de relva, medidos no período de 1. e maio de 1970 a 31 de dezembro de 2009, registrados na Estação Climatológica Principal de Santa Maria (latitude: 29043'S, longitude: 5343’W e altitude: 95 m). Classificaram-se os anos em anos de El Niño (EN), La Niña (LN) e Neutros (N), considerando-se o período de 1.\%/7 a 30/6 do ano seguinte. A média mensal de temperatura mínima de relva variou de $6,9{ }^{\circ} \mathrm{C}$ em julho a $17,3{ }^{\circ} \mathrm{C}$ em janeiro, com mínima absoluta de -8,4 ㄷ $\mathrm{C}$ junho e máxima absoluta de $28,6{ }^{\circ} \mathrm{C}$ em outubro. Há sinal do ENOS sobre a temperatura mínima de relva nos meses de outono, inverno e primavera, de modo que esta é maior em anos de EN, menor em anos de LN e intermediária em anos Neutros. Houve aumento na temperatura mínima de relva no período de 1970-2009 em abril, junho, outubro, novembro e dezembro, com início do aumento principalmente na década de 80. Nos demais meses não foram verificadas significativas tendências de ordem climática.

Palavras-chave: El Niño, La Niña, variabilidade climática, mudança climática, tendência das mínimas.

\section{Minimum temperature over short grass in Santa Maria, RS: climatology, interannual variability, and historical trend}

\begin{abstract}
The objective of this study was to calculate the descriptive statistics to characterize the climatology of minimum air temperature at $5 \mathrm{~cm}$ over short grass (Tmr) in Santa Maria, RS. A further objective was to associate the interannual variability of Tmr with the ENSO phenomenon and also to verify if there is a trend in the historical series for this meteorological variable. Data used in this study were daily minimum air temperature over short grass measured at the Meteorological Station in Santa Maria, RS, Brazil (29043'S, 53043'W and altitude of 95 m) from 1 $1^{\text {st }}$ May 1970 to 31 December 2009. Years were grouped in El Niño, La Niña, and Neutral years, from $1^{\text {st }}$ July to 30 June. Mean monthly minimum air temperature varied from $6.9^{\circ} \mathrm{C}$ in July to $17.3^{\circ} \mathrm{C}$ in January, with the lowest value of $-8.4^{\circ} \mathrm{C}$ in June and the highest value of $28.6{ }^{\circ} \mathrm{C}$ in October. There is an ENSO signal on the minimum air temperature over short grass during the months of Fall, Winter and Spring. Minimum air temperature is greater during El Niño, lower during La Niña and intermediate in Neutral years. There was increase in grass minimum temperature during the 1970-2009 period in April, June, October, November and December, with increased trends starting mainly in the 80's. Non-significant climatic trends were detected in the other months.
\end{abstract}

Key word: El Niño, La Niña, climate variability, climate change, minima trend. 


\section{INTRODUÇÃO}

A temperatura mínima de relva (Tmr - temperatura mínima do ar a $5 \mathrm{~cm}$ do solo coberto com grama) tem grande importância agrometeorológica, pois representa melhor a intensidade de resfriamento de superfícies vegetadas de porte baixo, tais como muitas culturas agrícolas e pastagens anuais, do que a temperatura mínima medida a $1,5 \mathrm{~m}$ ou a 2,0 $\mathrm{m}$ acima do solo, no interior do abrigo meteorológico nas Estaçóes Meteorológicas convencionais e automáticas respectivamente. Esse fato ocorre porque o termômetro fica exposto a céu aberto e mais próximo da vegetação onde ocorrem as trocas radiativas entre a superfície e a atmosfera (Heldwein et al., 1988). Em noites de intensa perda radiativa a diferença entre a temperatura mínima do ar no abrigo e a temperatura mínima de relva (Tma-Tmr) pode chegar a $5{ }^{\circ} \mathrm{C}$ (Bootsma, 1976; Ferreira et al., 2006). Em Santa Maria (RS), HeldweIn et al. (1988), relatam diferenças Tma-Tmr maiores que $4,5^{\circ} \mathrm{C}$ em dias com temperatura mínima no abrigo $\leq 6^{\circ} \mathrm{C}$ e que a diferença aumenta nas noites mais frias. As noites mais frias se caracterizam pela ocorrência de céu límpido, baixa umidade do ar e baixa velocidade do vento, condiçóes em que o fenômeno da inversão térmica na camada atmosférica próxima da superfície é mais intensa. Os últimos autores relatam também que, embora em número reduzido, podem ocorrer valores negativos da Tma-Tmr (em casos raros alcançaram $12^{\circ} \mathrm{C}$ ) em dias chuvosos ou encobertos por nuvens e/ou nevoeiros e dias com velocidade do vento elevada.

A Tmr é medida rotineiramente na Estação Meteorológica Principal de Santa Maria (RS), desde 1970. HeLDWEIN et al. (1988) analisaram os dados de Tmr deste local entre 5/10/1970 e 31/12/1984. Esta análise possibilitou a determinação de modelos de regressão linear múltipla para estimativa deste elemento meteorológico a partir de outros, tais como, temperatura mínima do ar no abrigo meteorológico, velocidade média diária do vento, grau de nebulosidade e pressão parcial de vapor. No entanto, 15 anos é um período curto para uma análise climatológica. Ao finalizar a primeira década do século XXI completamse quatro décadas de dados de Tmr em Santa Maria, o que representa uma série histórica mais apropriada para elaborar a climatologia deste elemento meteorológico, o que constituiu a primeira motivaçáo para este estudo.

Além da climatologia de um elemento meteorológico, é pertinente também determinar padróes de sua variabilidade interanual, pois muitas séries meteorológicas contém sinais de fenômenos oceânico-atmosféricos de grande escala como o El Niño Oscilação Sul (ENOS). O ENOS faz parte de uma variação irregular das condições normais do oceano e atmosfera na região do Pacífico tropical, que afeta o tempo e o clima em diversos lugares do globo terrestre (CANE, 2001). Um dos extremos dessa variação é a fase quente, denominada El Niño, caracterizada pelo aquecimento anormal das águas na regiâo equatorial simultaneamente com diminuição da pressão atmosférica no Pacífico tropical leste. O outro extremo do ENOS é a fase fria ou fase positiva, denominada La Niña, caracterizada pelo resfriamento anormal das águas e aumento da pressão atmosférica na região leste do Pacífico (Berlato e Fontana, 2003). Berlato e Fontana (2003) utilizaram o Índice de Oscilação Sul (IOS) e a Temperatura da Superfície do Mar (TSM) na caracterização das diferentes fases desse fenômeno oceânico-atmosférico.

O ENOS causa variabilidade interanual de alguns elementos meteorológicos em diferentes locais incluindo o Rio Grande do Sul, como precipitação pluvial, temperatura mínima e máxima do ar, brilho solar, evaporaçẫo do tanque Classe A e umidade relativa do ar (Grimm et al., 1998, 2000; Cunha et al., 1999; Berlato e Fontana, 2003; Streck et al., 2008). No entanto, para o elemento meteorológico temperatura mínima de relva, a caracterização da variabilidade interanual ainda não foi realizada para Santa Maria, o que constituiu a segunda motivação para a realização este estudo. Uma terceira motivação é o crescente interesse na análise de tendências da Tmr em função do possível aquecimento global, pois a agricultura é um setor vulnerável (IPCC, 2007).

O objetivo deste trabalho foi calcular as estatísticas descritivas para caracterizar a climatologia da temperatura mínima de relva em Santa Maria (RS), associar sua variabilidade interanual com o fenômeno ENOS e verificar se há tendência de alteração na série histórica deste elemento meteorológico.

\section{MATERIAL E MÉTODOS}

Foram utilizados dados diários de Tmr medida por meio de um termômetro de mínima de álcool instalado a $5 \mathrm{~cm}$ sobre o solo gramado, no período de $1 .^{\circ}$ de maio de 1970 a 31 de dezembro de 2009, na Estação Meteorológica Principal de Santa Maria (ECPSM), pertencente ao 8. ${ }^{\circ}$ Distrito de Meteorologia do Instituto Nacional de Me-

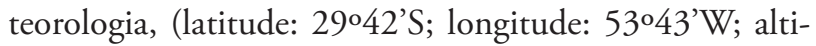
tude: $95 \mathrm{~m}$ ). O clima da região é Cfa (Subtropical sem estaçáo seca e com verôes quentes) segundo a classificação de Köppen (Kuinchtner e Buriol, 2001).

A consistência dos dados da série histórica foi determinada por meio da metodologia usada por Estefanel et al. (1990) e Buriol et al. (2006). Para isto, utilizaram-se os valores médios mensais acumulados de temperatura mínima como variável dependente (eixo das ordenadas) e os anos da série histórica como variável independente (eixo das abscissas). A série é considerada homogênea no caso dos dados se ajustarem a uma única reta ascendente (Buriol et al., 2006). Durante o período de observaçôes ocorreram falhas em somente 198 dias (1,4\% do total) sem leitura.

Os anos, a intensidade, a duraçáo e o período de ocorrência em meses dos eventos de El Nińo, La Niña e Neutros utilizados estão na tabela 1 . Os valores de anomalia 
Tabela 1. Classificação $(\mathrm{Cl})$, intensidade (I), duração (D, em meses), período de ocorrência do fenômeno ENOS (mês-mês), estatísticas descritivas [média $(\mathrm{M})$ e desvio-padrão (DP) e coeficiente de variação (CV, em \%), valores mínimos (Mín.) e máximos (Máx.)] absoluto] da temperatura mínima de relva $\left({ }^{\circ} \mathrm{C}\right)$ em Santa Maria (RS), no período de 1970-2009 em cada evento e ano do fenômeno ENOS

\begin{tabular}{|c|c|c|c|c|c|c|c|c|}
\hline Ano & $\mathrm{Cl}^{*}$ & $I^{*}$ & D & Período & $\mathrm{M} \pm \mathrm{DP}$ & Mín. & Máx. & CV \\
\hline 1970-1971 & $\mathrm{LN}$ & M & 12 & $07-06$ & $10,5 \pm 6,9$ & $-8,4(17 / 06 / 71)$ & $24,0(24 / 01 / 71)$ & 65,9 \\
\hline 1971-1972 & $\mathrm{LN}$ & $f$ & 7 & $07-01$ & $12,4 \pm 5,4$ & $-4,3(02 / 07 / 71)$ & $25,5(19 / 12 / 71)$ & 43,8 \\
\hline 1972-1973 & EN & $\mathrm{F}$ & 11 & $05-03$ & $12,8 \pm 6,1$ & $-4,5(04 / 08 / 72)$ & $24,6(06 / 01 / 73)$ & 48,0 \\
\hline 1973-1974 & $\mathrm{LN}$ & M & 15 & $05 / 73-07 / 74$ & $11,4 \pm 6,2$ & $-4,6(13 / 06 / 74)$ & $23,2(05 / 02 / 74)$ & 54,4 \\
\hline 1974-1975 & $\mathrm{LN}$ & $f$ & 10 & $09-06$ & $11,2 \pm 6,0$ & $-4,8(09 / 08 / 74)$ & $24,0(15 / 02 / 75)$ & 53,5 \\
\hline 1975-1976 & $\mathrm{LN}$ & M & 11 & $07-05$ & $11,2 \pm 5,6$ & $-6,4(30 / 06 / 76)$ & $24,8(13 / 01 / 76)$ & 50,3 \\
\hline 1976-1977 & EN & $f$ & 6 & $09-02$ & $11,4 \pm 6,6$ & $-7,9(10 / 07 / 76)$ & $22,4(09 / 01 / 77)$ & 57,5 \\
\hline 1977-1978 & EN & $f$ & 6 & $09-02$ & $10,8 \pm 7,0$ & $-7,6(06 / 06 / 78)$ & $23,9(27 / 07 / 77)$ & 64,5 \\
\hline 1978-1979 & $N$ & - & - & - & $10,8 \pm 6,2$ & $-6,4(15 / 06 / 79)$ & $21,6(26 / 11 / 78)$ & 57,8 \\
\hline 1979-1980 & $\mathrm{N}$ & - & - & - & $12,4 \pm 6,4$ & $-7,0(04 / 06 / 80)$ & $24,8(11 / 04 / 80)$ & 51,4 \\
\hline 1980-1981 & $\mathrm{N}$ & - & - & - & $11,4 \pm 6,7$ & $-7,6(31 / 07 / 80)$ & $21,6(12 / 02 / 81)$ & 58,4 \\
\hline 1981-1982 & $N$ & - & - & - & $11,4 \pm 6,0$ & $-4,8(29 / 05 / 82)$ & $26,8(09 / 09 / 81)$ & 52,7 \\
\hline 1982-1983 & EN & $\mathrm{F}$ & 14 & $05 / 82-06 / 83$ & $12,4 \pm 6,3$ & $-8,2(06 / 06 / 83)$ & $25,1(26 / 08 / 82)$ & 51,0 \\
\hline 1983-1984 & $\mathrm{N}$ & - & - & - & $12,3 \pm 7,1$ & $-5,4(28 / 06 / 84)$ & $26,4(29 / 08 / 83)$ & 57,4 \\
\hline 1984-1985 & $\mathrm{LN}$ & $f$ & 12 & $10-09$ & $11,0 \pm 6,5$ & $-6,2(26 / 08 / 84)$ & $25,2(07 / 01 / 85)$ & 58,9 \\
\hline 1985-1986 & $N$ & - & - & - & $11,9 \pm 6,0$ & $-7,0(11 / 07 / 85)$ & $23,5(17 / 01 / 86)$ & 50,6 \\
\hline 1986-1987 & EN & M & 10 & $09-06$ & $11,1 \pm 6,8$ & $-7,4(24 / 06 / 87)$ & $23,2(14 / 09 / 86)$ & 60,8 \\
\hline 1987-1988 & EN & M & 8 & $07-02$ & $10,6 \pm 6,9$ & $-6,0(02 / 06 / 88)$ & $\begin{array}{c}22,6(16 / 07 / 87 \text { e } \\
18 / 01 / 88)\end{array}$ & 64,7 \\
\hline 1988-1989 & $\mathrm{LN}$ & $\mathrm{F}$ & 13 & 05/88-05/89 & $11,0 \pm 6,1$ & $-5,8(11 / 07 / 84)$ & $24,0(24 / 08 / 88)$ & 55,5 \\
\hline 1989-1990 & $\mathrm{N}$ & - & - & - & $11,3 \pm 6,9$ & $-6,4(06 / 07 / 89)$ & $\begin{array}{c}22,0(30 / 01 / 90 \\
08 / 02 / 90 \text { e } 11 / 02 / 90)\end{array}$ & 61,2 \\
\hline 1990-1991 & $N$ & - & - & - & $11,7 \pm 6,5$ & $\begin{array}{c}6,6(28 / 07 / 90 \text { e } \\
29 / 08 / 90)\end{array}$ & $\begin{array}{c}23,6(28 / 05 / 91 \mathrm{e} \\
29 / 05 / 91)\end{array}$ & 55,2 \\
\hline 1991-1992 & EN & M & -15 & 05/91-07/92 & $12,7 \pm, 5$ & $-7,0(14 / 07 / 91)$ & $28,6(15 / 10 / 91)$ & 50,9 \\
\hline 1992-1993 & $\mathrm{N}$ & - & & - & $11,3 \pm 6,6$ & $-7,2(02 / 08 / 92)$ & $23,0(02 / 01 / 93)$ & 58,4 \\
\hline 1993-1994 & $\mathrm{N}$ & - & - & - & $11,6 \pm 6,4$ & $-7,0(16 / 07 / 93)$ & $23,6(25 / 01 / 94)$ & 55,3 \\
\hline 1994-1995 & EN & $f$ & 9 & $07-03$ & $12,1 \pm 6,4$ & $-6,0(11 / 07 / 94)$ & $\begin{array}{c}23,0(21 / 07 / 94 \\
05 / 01 / 95 \text { e } 17 / 01 / 95)\end{array}$ & 53,2 \\
\hline 1995-1996 & $\mathrm{LN}$ & $f$ & 7 & $09-03$ & $11,9 \pm 6,7$ & $-7,4(05 / 08 / 95$ & $23,8(27 / 07 / 95)$ & 56,8 \\
\hline 1996-1997 & $\mathrm{N}$ & - & - & - & $11,5 \pm 6,8$ & $-6,0(05 / 07 / 96)$ & $23,4(29 / 01 / 97)$ & 58,6 \\
\hline 1997-1998 & EN & $\mathrm{F}$ & 12 & $05-04$ & $12,6 \pm 6,1$ & $-3,2(05 / 08 / 97)$ & $25,8(19 / 08 / 97)$ & 48,5 \\
\hline 1998-1999 & $\mathrm{LN}$ & M & 12 & $07-06$ & $12,3 \pm 5,3$ & $-3,0(06 / 06 / 99)$ & 21,6 (07/02/99) & 43,6 \\
\hline 1999-2000 & $\mathrm{LN}$ & M & 12 & $07-06$ & $12,4 \pm 5,6$ & $-3,4(15 / 08 / 99)$ & $23,8(31 / 08 / 99)$ & 45,3 \\
\hline 2000-2001 & $\mathrm{LN}$ & $f$ & 5 & $10-02$ & $12,8 \pm 6,9$ & $-6,5(14 / 07 / 00)$ & $25,4(30 / 12 / 00)$ & 54,1 \\
\hline 2001-2002 & $N$ & - & - & - & $13,5 \pm 5,7$ & $-5,2(25 / 06 / 02)$ & $26,2(30 / 03 / 02)$ & 42,2 \\
\hline $2002-2003$ & EN & M & 11 & $05-03$ & $13,1 \pm 5,8$ & $-1,2(12 / 07 / 02)$ & $23,8(09 / 02 / 03)$ & 44,2 \\
\hline $2003-2004$ & $\mathrm{~N}$ & - & - & - & $12,0 \pm 6,1$ & $-5,8(12 / 07 / 03)$ & $22,6(05 / 02 / 04)$ & 50,8 \\
\hline 2004-2005 & EN & $f$ & 8 & $07-02$ & $12,4 \pm 5,8$ & $-6,2(11 / 07 / 04)$ & $23,4(31 / 01 / 05)$ & 46,6 \\
\hline $2005-2006$ & $\mathrm{~N}$ & - & - & - & $12,2 \pm 6,0$ & $-3,2(23 / 05 / 06)$ & $24,4(16 / 01 / 06)$ & 49,2 \\
\hline $2006-2007$ & EN & $f$ & 6 & $08-01$ & $13,0 \pm 6,7$ & $-4,8(02 / 08 / 06)$ & $24,4(09 / 08 / 06)$ & 51,2 \\
\hline $2007-2008$ & $\mathrm{LN}$ & M & 10 & $08-05$ & - & - & - & - \\
\hline 2008-2009 & $\mathrm{N}$ & - & - & - & $12,0 \pm 5,7$ & $-3,2(03 / 06 / 09)$ & $25,4(03 / 09 / 08)$ & 47,8 \\
\hline El Niños & & & & & $12,1 \pm 6,4$ & $-5,8$ & 24,2 & 53,4 \\
\hline La Niñas & & & & & $11,6 \pm 6,1$ & $-5,5$ & 24,1 & 52,9 \\
\hline Neutros & & & & & $11,8 \pm 6,3$ & $-5,9$ & 23,9 & 53,8 \\
\hline
\end{tabular}


da TSM foram obtidos de NOAA (2010) e a classificação da intensidade do ENOS foi realizada segundo os critérios usados em Paula (2009), utilizando-se o Índice Oceânico do Nińo (ION) retirados de NoAA (2010): El Niño fraco quando o ION é entre 0,5 e 0,9 , El Nińo moderado quando o ION é entre 1,0 e 1,4 e El Niño forte quando o ION é maior ou igual a 1,5 ; La Nińa fraca quando o ION é entre $-0,5$ e - 0,9 , La Niña moderada quando o ION é entre -1,0 e -1,4 e La Niña forte quando o ION é menor ou igual a $-1,5$.

$\mathrm{Na}$ análise da climatologia da $\mathrm{Tmr}$, foram calculadas as estatísticas descritivas média, valor mínimo absoluto, valor máximo absoluto, desvio-padrão e coeficiente de variação. $\mathrm{O}$ número de noites com geadas foi também estimado, definindo-se este último por $\mathrm{Tmr}<0{ }^{\circ} \mathrm{C}$.

$\mathrm{Na}$ análise em relaçáo ao fenômeno ENOS, os valores diários de Tmr foram agrupados em anos de El Niño, La Niña e Neutros, iniciando no segundo semestre do ano $(1 . \% / 7)$ e finalizando no primeiro semestre do ano seguinte (30/6), conforme usado por Paula (2010). Foram calculados também as estatísticas descritivas médias, o desvio-padrão, coeficiente de variação, valor mínimo e valor máximo, e constituídos gráficos de caixa, com média, desvio-padrão, mediana (percentil 50) e percentis 10, 25, 75 e 90 em cada evento do ENOS. A série temporal de Tmr de 1970-2009 (média, mínima e máxima absoluta mensal) também foi usada para detectar periodicidades (ciclos ou oscilaçôes e suas frequências) relacionadas ao ENOS, utilizando-se o método da função densidade espectral de potências calculada com o Teorema de Wiener sobre as médias, as mínimas e as máximas absolutas mensais e sazonais de temperatura com defasagem (lags) de 10 anos para detectar ciclos anuais relacionados ao fenômeno ENOS (Souza et al., 2009; STreck et al., 2009). Para lag de 10 anos, a densidade espectral foi calculada após aplicar-se um filtro passa-banda de 20 anos na série histórica. Considerou-se que os harmônicos (que representam o ciclo ou frequência das oscilações) são significativos quando os valores da densidade espectral são superiores aos valores de probabilidade de $95 \%$ pelo teste do quiquadrado (Souza et al., 2009).

A tendência temporal das séries mensais de Tmr (média, mínima e máxima absoluta) foi avaliada pelo teste não paramétrico de Mann-Kendall (MK) a 5\% de probabilidade de erro tipo I, conforme descrito em BACK (2001). O MK foi aplicado em cada uma das 12 séries mensais assumindo-se a inexistência de autocorrelaçōes significativas uma vez que a temperatura mensal de um ano náo deve ter correlação com a do ano seguinte ou do ano anterior, e assim nâo é necessário usar o teste modificado de Mann-Kendall (Hamed e RaO, 1998; Basistha et al., 2009; Shahid, 2009). Para os meses em que o MK indicou tendências significativas, realizou-se uma regressão linear simples considerando como variável dependente a Tmr e como variável independente os anos (1 a 40). O coeficiente angular desta regressão representa a mudança na série histórica e é significativo quando o intervalo de confiança da sua estimativa náo inclui o valor zero (BACK, 2001). Com o teste MK, obtêm-se também o ponto (ano) aproximado de início da tendência nas séries históricas, mas além desta estimativa, usou-se também o teste de Pettitt para estimar o ano de início da tendência (BACK, 2001).

\section{RESULTADOS E DISCUSSÃO}

Verificou-se que, em todos os meses, a série é homogênea (Figura 1), pois os dados médios mensais acumulados em função dos anos ajustam-se a uma única reta ascendente, com valores do coeficiente angular (declividade) altamente significativo $(\mathrm{p}<0,00001)$ e do coeficiente de determinação maior que 0,999 . Esses valores indicam que a série pode ser integralmente usada por não haver indícios de problemas de leituras e/ou de equipamento, ou mesmo de alteraçôes das condições de contorno da estação climatológica (Buriol et al., 2006).

As estatísticas descritivas da Tmr para os doze meses do ano, estaçôes do ano, semestres e ano estáo na tabela 2. $\mathrm{O}$ mês com menor média $\left(6,9^{\circ} \mathrm{C}\right)$ é julho, e a mínima absoluta $\left(-8,4^{\circ} \mathrm{C}\right)$ também ocorreu em junho (17/6/71), próximo ao solstício de inverno. Para confirmar a veracidade da observação de $17 / 6 / 71$, foi feita uma consulta aos dados meteorológicos da noite anterior às 21 horas e a do dia em questão, às 9 horas. A temperatura do ar foi de 2,3 e $0{ }^{\circ} \mathrm{C}$, e a velocidade do vento foi zero, respectivamente, nos dois horários. $\mathrm{O}$ mês com maior média $\left(17,3^{\circ} \mathrm{C}\right)$ é janeiro, mas a máxima absoluta $\left(28,6^{\circ} \mathrm{C}\right)$ ocorreu em outubro (15/10/91). Consultando novamente os dados das 21 horas do dia anterior (14/10/91) e das 9 horas desse dia, verificou-se que a temperatura do ar foi de 32,8 e $31,6^{\circ} \mathrm{C}$ e a velocidade do vento foi de, respectivamente, 5,5 e $10,0 \mathrm{~m} / \mathrm{s}$, em ambos horários com direção do vento do quadrante norte. Conclui-se, dessa forma, que o valor alto de $\mathrm{Tmr}$ de 15/10/91 é realístico, típico de situação de vento norte em Santa Maria (Heldwein et al., 2003).

Sazonalmente, a Tmr média do verão foi $16,7^{\circ} \mathrm{C}$, seguido do outono $\left(12,1{ }^{\circ} \mathrm{C}\right)$, primavera $\left(11,4^{\circ} \mathrm{C}\right)$ e inverno $\left(7,3^{\circ} \mathrm{C}\right)$. A média anual de Tmr é de $11,9^{\circ} \mathrm{C}$, sendo o 1. ${ }^{\circ}$ semestre do ano mais quente, com média de $12,9{ }^{\circ} \mathrm{C}$ quando comparado com o $2 .^{\circ}$ semestre, com média de $10,8^{\circ} \mathrm{C}$. O desvio-padrão das médias mensais variou de $3,6^{\circ} \mathrm{C}$ em janeiro a $6,5^{\circ} \mathrm{C}$ em junho e julho e o coeficiente de variação de $21,1 \%$ em janeiro a $93,6 \%$ em julho. Tem-se, assim, alta variabilidade deste elemento climático ao longo do ano, mas especialmente no inverno (junho, julho e agosto). Esta alta variabilidade mensal está associada a frentes frias que, semanalmente, atingem o Estado do Rio Grande do Sul. Após a passagem frontal, a temperatura tende a diminuir intensamente durante a noite 

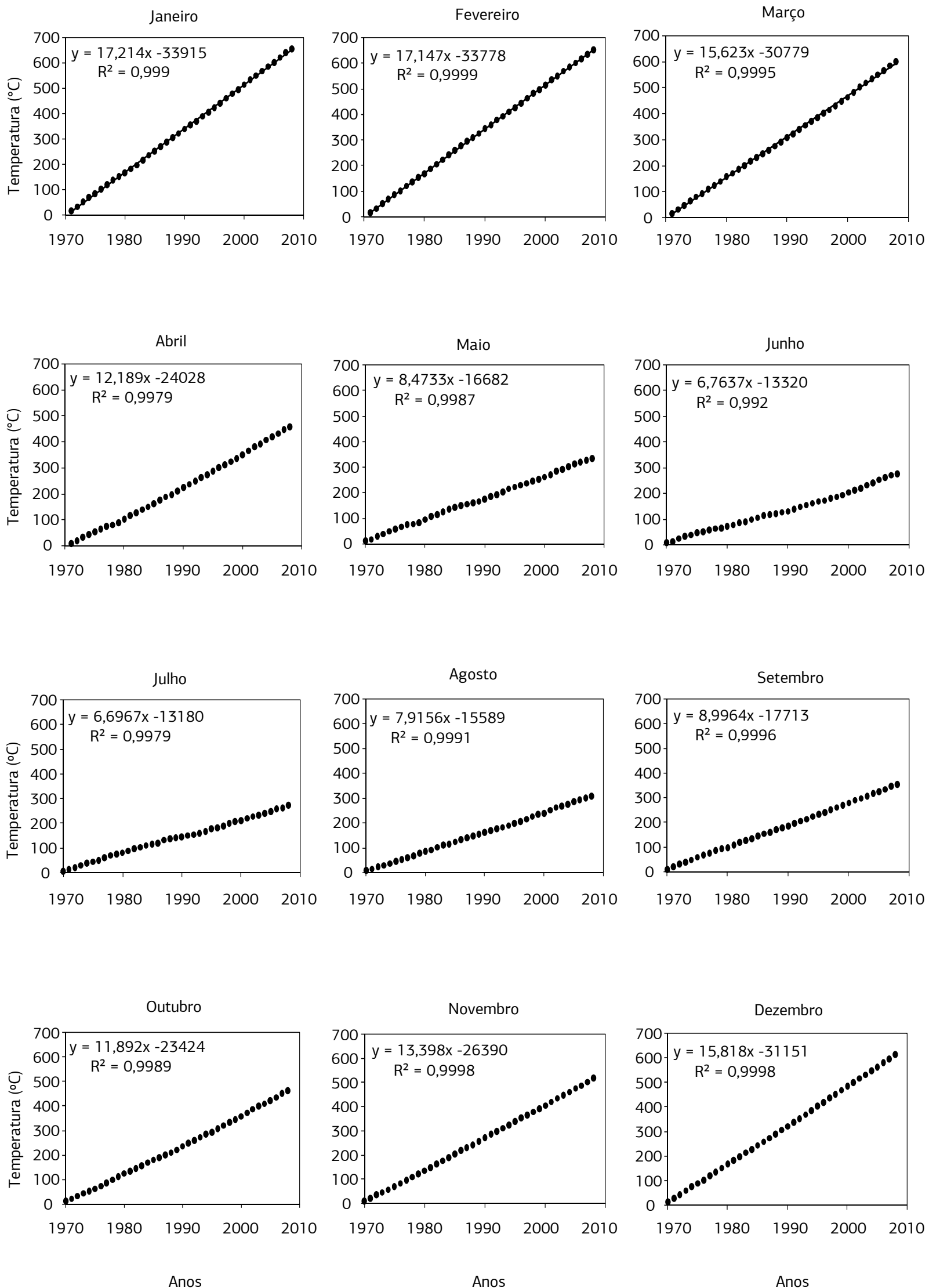

Figura 1. Médias mensais acumuladas de temperatura mínima de relva $\left({ }^{\circ} \mathrm{C}\right)$ para a Estação Climatológica Principal de Santa Maria no período de 1970-2009, em Santa Maria (RS). 
Tabela 2. Estatísticas descritivas (média, valor mínimo absoluto, valor máximo absoluto, desvio-padrão e coeficiente de variação) da temperatura mínima de relva $\left({ }^{\circ} \mathrm{C}\right)$ para os doze meses do ano e para os períodos sazonais, semestrais e anual, em Santa Maria (RS), nos 40 anos (1970-2009). Entre parênteses estão indicadas as datas (dia/mês/ano) da ocorrência do respectivo valor extremo absoluto de temperatura ocorrido

\begin{tabular}{lccccc} 
Período ${ }^{(1)}$ & Média & Valor Mínimo Absoluto & Valor Máximo Absoluto & DP & CV (\%) \\
\hline Janeiro & 17,3 & $3,2(16 / 01 / 92)$ & $25,2(07 / 01 / 85)$ & 3,6 & 21,1 \\
\hline Fevereiro & 17,2 & $1,2(19 / 02 / 93)$ & $24,3(08 / 02 / 73)$ & 3,7 & 21,6 \\
\hline Março & 15,8 & $2,0(29 / 03 / 76)$ & $26,2(30 / 03 / 02)$ & 4,0 & 25,4 \\
\hline Abril & 12,0 & $-1,6(16 / 04 / 80$ e $19 / 04 / 91)$ & $24,8(11 / 04 / 80)$ & 5,2 & 43,3 \\
\hline Maio & 8,6 & $-6,6(28 / 05 / 78)$ & $23,6(28 / 05 / 91$ e $29 / 05 / 91)$ & 5,9 & 68,0 \\
\hline Junho & 7,0 & $-8,4(17 / 06 / 71)$ & $23,6(21 / 06 / 07)$ & 6,5 & 93,3 \\
\hline Julho & 6,9 & $-7,9(10 / 07 / 76)$ & $23,9(27 / 07 / 77)$ & 6,5 & 93,6 \\
\hline Agosto & 7,9 & $-7,4(05 / 08 / 95)$ & $26,4(29 / 08 / 83)$ & 6,1 & 76,5 \\
\hline Setembro & 9,1 & $-5,2(19 / 09 / 79)$ & $26,8(09 / 09 / 81)$ & 5,5 & 60,6 \\
\hline Outubro & 11,9 & $-1,8(23 / 10 / 86)$ & $28,6(15 / 10 / 91)$ & 4,9 & 40,9 \\
\hline Novembro & 13,3 & $0,2(05 / 11 / 92)$ & $25,4(30 / 11 / 09)$ & 4,4 & 32,9 \\
\hline Dezembro & 15,8 & $2,2(04 / 12 / 70)$ & $25,5(19 / 12 / 71)$ & 3,8 & 24,3 \\
\hline Verão & 16,7 & 1,2 & 25,5 & 3,8 & 22,7 \\
\hline Outono & 12,1 & $-6,6$ & 26,2 & 5,9 & 48,6 \\
\hline Inverno & 7,3 & $-8,4$ & 26,4 & 6,4 & 87,5 \\
\hline Primavera & 11,4 & $-5,2$ & 28,6 & 5,2 & 45,9 \\
\hline $1 .{ }^{\circ}$ semestre & 12,9 & $-8,4$ & 26,2 & 6,4 & 50,0 \\
\hline 2. ${ }^{\circ}$ semestre & 10,8 & $-7,9$ & 28,6 & 6,1 & 56,9 \\
\hline Anual & 11,9 & $-8,4$ & 28,6 & 6,3 & 53,2 \\
\hline
\end{tabular}

( ${ }^{1}$ Período: Verăo = dezembro, janeiro e fevereiro; Outono = março, abril e maio; Inverno = junho, julho e agosto; Primavera = setembro, outubro e novembro; Primeiro semestre $=$ janeiro junho; Segundo semestre $=$ julho a dezembro.

Tabela 3. Número de noites com geada em meses nos 40 anos de observação e a média por ano em Santa Maria (RS), no período de 1970-2009

\begin{tabular}{lcc} 
Mês & Ocorrência de geada & Média/ano \\
\hline Janeiro & - & - \\
\hline Fevereiro & - & - \\
\hline Março & - & - \\
\hline Abril & 11 & 0,3 \\
\hline Maio & 96 & 2,4 \\
\hline Junho & 202 & 5,1 \\
\hline Julho & 206 & 5,2 \\
\hline Agosto & 124 & 3,1 \\
\hline Setembro & 78 & 2,0 \\
\hline Outubro & 7 & 0,2 \\
\hline Novembro & - & - \\
\hline Dezembro & - & - \\
\hline Total & 724 & 18,1 \\
\hline
\end{tabular}

devido à predominância do ar polar, frio e seco, que determina intensa perda de energia radiativa pela superfície. No inverno, as massas de ar polar são mais intensas e as noites mais longas, aumentando ainda mais o esfriamento noturno da superfície. Após duas ou três noites de intenso esfriamento, a massa de ar polar, mesmo no inverno, perde força e se aquece devido ao centro do Anticiclone Migratório Polar se posicionar na região tropical litorânea do Brasil, aumentando seu conteúdo absoluto de vapor d'água e, muitas vezes com vento do quadrante norte (Heldwein et al., 2003). Esta organização sinótica leva a um aumento do efeito estufa da atmosfera e o transporte turbulento de calor sensível entre as camadas próximas da superfície, respectivamente, diminuindo o esfriamento noturno até a passagem de nova frente.

A climatologia das mínimas absolutas de Tmr também define o período em que, climatologicamente, ocorrem geadas para os cultivos agrícolas. Nos 40 anos de observaçôes, ocorreram 724 geadas de relva, com média de 18 por ano e o período livre de geadas na relva é de novembro a março (Tabela 3). Já a climatologia dos valores máximos absolutos de temperatura mínima de relva indica que ocorrem temperaturas acima de $23{ }^{\circ} \mathrm{C}$ em todos os meses, mesmo no inverno, confirmando a alta variabilidade deste elemento climático. Estas altas temperaturas mínimas durante o inverno são prejudiciais às culturas frutíferas caducifólias perenes como videira e pessegueiro, pois reduzem a disponibilidade de frio para a quebra de dormência e podem interromper o período de repouso invernal. Como consequência pode haver brotação das gemas de forma desuniforme na planta e antecipadamente durante o inverno, quando a temperatura pode, ainda, baixar a níveis de congelamento dos tecidos, causando prejuízos severos nos pomares.

As estatísticas descritivas nos anos de El Niño, La Niña e Neutros estão na tabela $1 . \mathrm{Na}$ análise do ENOS, o ano 2007-2008 não foi usado, pois não há dados de 

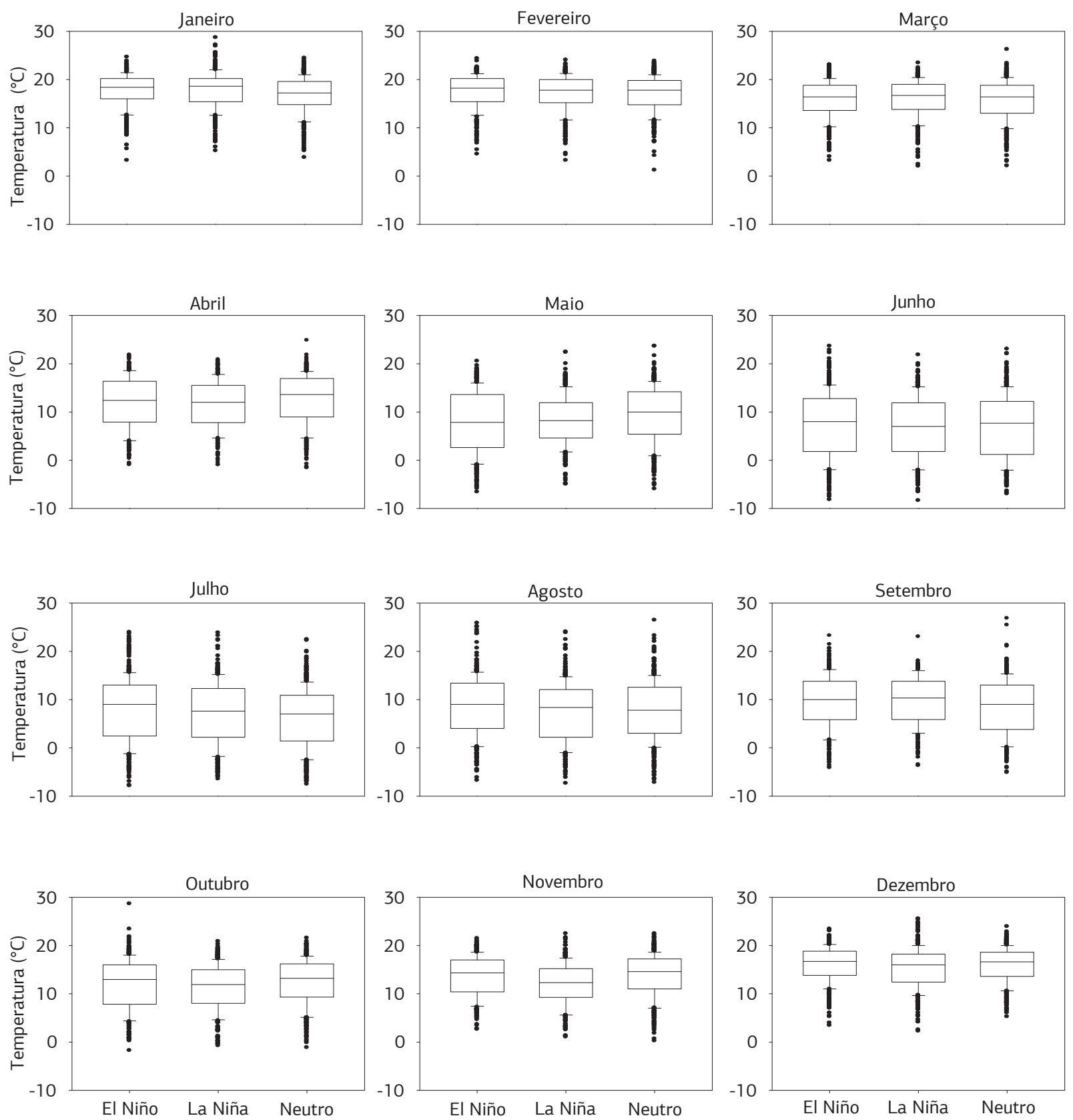

Figura 2. Distribuição dos valores diários de temperatura mínima de relva no período de 1970-2009 durante os meses do ano associada aos eventos de El Niño, La Niña e Neutros em Santa Maria, RS. A linha cheia horizontal, no interior das caixas, representa o percentil de 50 (mediana); o final das caixas representa os percentis de 25 e 75 ; as barras representam os percentis de 10 e 90 ; e os pontos representam os valores extremos.

Tmr de 20/11/07 a 30/4/08, totalizando 162 dias sem leitura nesse ano de El Niño. A média dos anos (de julho a junho) foi maior nos anos de El Niño $\left(12,1^{\circ} \mathrm{C}\right)$, menor nos anos de La Nińa $\left(11,6^{\circ} \mathrm{C}\right)$ e intermediária nos anos Neutros $\left(11,8^{\circ} \mathrm{C}\right)$, indicando resfriamento noturno mais intenso em condições de La Niña e menos intenso nas condiçốes de El Niño. Os menores valores absolutos (mínimos) foram $-8,2{ }^{\circ} \mathrm{C}$ em 6/6/1983 (ano de El Niño),
$-8,4{ }^{\circ} \mathrm{C}$ em $17 / 6 / 1971$ (ano de La Nińa) e $-7,6{ }^{\circ} \mathrm{C}$ em $31 / 7 / 1980$ (ano Neutro), e os maiores valores absolutos (máximos) foram de $28,6{ }^{\circ} \mathrm{C}$ em $15 / 10 / 1991$ (ano de $\mathrm{El}$ Niño), de $25,5^{\circ} \mathrm{C}$ em 19/12/1971 (ano de La Niña) e de $26,8^{\circ} \mathrm{C}$ em 9/9/1981 (ano Neutro). O desvio-padrão anual médio nos anos de El Niño, La Niña e Neutros foram $6,4^{\circ} \mathrm{C}, 6,1^{\circ} \mathrm{C}$ e $6,3{ }^{\circ} \mathrm{C}$ e o coeficiente de variação foram $53,4 \%, 52,9 \%$ e $53,8 \%$, respectivamente, ocor- 
rendo, portanto, variabilidade similar e elevada nos três agrupamentos de anos.

Os percentis representados nos gráficos de caixa para a temperatura média mensal durante os doze meses do ano nos três agrupamentos do ENOS estão relacionados na figura 2. É possível visualizar o sinal do ENOS em todos os meses do ano, mas principalmente em abril, maio, julho, agosto, outubro e novembro. Estes resultados coincidem com os dois períodos de maior sinal do ENOS nos meses do ano sobre a precipitaçáo pluvial no Rio Grande do Sul (Fontana e Berlato, 1997; Berlato e Fontana, 2003): o primeiro é na primavera e no início do verão, com ênfase em outubro e novembro, e o segundo período (repique) no fim do outono e início do inverno do ano seguinte, especialmente em maio e junho. Também em maio e novembro, STRECK et al. (2008) relataram maior sinal do ENOS sobre a evaporaçáo do tanque Classe A e a umidade relativa do ar em Santa Maria. Pela análise dos gráficos de caixa da figura 2, os percentis são maiores em anos de La Nińa, menores em anos Neutros e intermediários em anos de El Niño em janeiro, março e setembro. Em fevereiro, julho e agosto, os percentis são maiores em anos de El Niño, menores em anos Neutros e intermediários em anos de La Niña. Em abril, outubro, novembro e dezembro os percentis são maiores em anos Neutros, menores em anos de La Nińa e intermediários em anos de El Niño. Em maio os percentis são maiores em anos Neutros, menores em anos de El Niño e intermediários em anos de La Nińa, e em junho são maiores em anos de El Niño e menores em anos de La Niña.

Tabela 4. Duraçấo dos ciclos de temperatura mínima de relva $\left({ }^{\circ} \mathrm{C}\right)$, significativos pelo teste qui-quadrado, estimados pela análise de densidade espectral de potências para a defasagem (lag) de 10 anos após o filtro passa-banda de 20 anos na série histórica de temperatura mínima de relva de Santa Maria (RS), para os doze meses do ano e para cada estaçáo do período de 1970-2009

\begin{tabular}{lccc} 
Mês/estação & Média & Mínimo & Máximo \\
\hline Janeiro & $3-5$ & $3-5$ & $4-5$ \\
\hline Fevereiro & $3-5$ & $3-5$ & $4-5$ \\
\hline Março & $4-6$ & $4-6$ & $3-4$ \\
\hline Abril & $3-5$ & $3-4$ & $3-4$ \\
\hline Maio & $4-5$ & $4-5$ & $3-4$ \\
\hline Junho & $3-5$ & $4-5$ & $3-5$ \\
\hline Julho & $4-5$ & $4-5$ & $4-6$ \\
\hline Agosto & $4-5$ & $4-5$ & $4-5$ \\
\hline Setembro & $4-5$ & $3-5$ & $4-5$ \\
\hline Outubro & $3-4$ & $3-5$ & $4-5$ \\
\hline Novembro & $3-5$ & $4-5$ & $3-5$ \\
\hline Dezembro & $3-5$ & $4-6$ & $4-5$ \\
\hline Verão & $3-5$ & $3-5$ & $4-6$ \\
\hline Outono & $3-5$ & $4-5$ & $3-5$ \\
Inverno & $4-5$ & $4-6$ & $4-5$ \\
\hline Primavera & $3-5$ & $4-5$ & $4-5$
\end{tabular}

Média $=$ Média mensal de temperatura mínima de relva; Mínimo= Menor valor absoluto de temperatura mínima de relva; Máximo= Maior valor absoluto de temperatura mínima de relva.
Em resumo, em abril e maio os anos Neutros têm menor resfriamento (a temperatura mínima de relva é maior) e não há diferença entre anos de La Niña e El Niño. Em junho, anos de La Niña tem Tmr menor. Julho, agosto e setembro têm Tmr menor em anos Neutros e nos dois primeiros meses têm Tmr maior em anos de El Niño. Outubro e novembro têm Tmr menor nos anos de La Niña e anos de El Niño e Neutros são parecidos entre si. De dezembro a março náo há tendência exceto janeiro com Tmr menor em anos Neutros.

A densidade espectral para periodicidade no ENOS considerando-se as médias, os mínimos e os máximos absolutos mensais e sazonais de temperatura mínima de relva com defasagem de 10 anos e após o filtro passa-banda de 20 anos está na tabela 4. Para a média mensal, os ciclos significativos foram de 3 a 4 anos em outubro; 4 a 5 anos em maio, julho, agosto, setembro e na estação de inverno; de 3 a 5 anos em janeiro, fevereiro, abril, junho, novembro, dezembro e nas estaçóes de veráo, outono e primavera, e 4 a 6 anos em março. Para os menores valores (mínimos) absolutos e os maiores valores (máximos) absolutos mensais, os ciclos significativos variaram de 3 a 6 anos, dependendo do mês e da estação (Tabela 4). Realizouse uma análise espectral adicional considerando-se uma defasagem de 10 anos, sem filtro passa-banda, visando confirmar os resultados da análise espectral com filtro. Os resultados desta última análise indicaram náo haver ciclos significativos nos quatro primeiros meses do ano para a média mensal e menores valores (mínimos) - de janeiro a março para os maiores valores (máximos) e na estação de verâo para todas as variáveis; esse resultado indica sinal mais pronunciado do ENOS no espectro da Tmr no outono, inverno e primavera; no verão é desconsiderável o efeito do ENOS sobre a Tmr. Esta informação pode ser utilizada no planejamento agrícola, visando à redução dos riscos de geada tardia (Primavera) para a floração de culturas de inverno como o trigo, e quebra de dormência de frutíferas temperadas perenes durante o inverno.

$\mathrm{Na}$ análise temporal da série histórica da média, mínima e máxima absoluta mensal de Tmr, o teste de Mann-Kendall indicou significativas tendências crescentes (positiva) em abril, outubro, novembro e dezembro para a média mensal; em abril, junho, outubro, novembro e dezembro para as mínimas, e em abril e novembro para as máximas absolutas mensais. Na figura 3 está representada a série temporal da média, valores mínimo e máximo absolutos em cada mês, com as equaçōes de regressão nas variáveis e meses em que o teste de MannKendall foi significativo e o intervalo de confiança do coeficiente angular da regressão linear não incluiu o valor zero. Para abril e junho, o aumento na Tmr variou de $0,48{ }^{\circ} \mathrm{C} /$ década (valor máximo absoluto de abril) a 0,97 ${ }^{\circ} \mathrm{C} /$ década (média de abril), e de outubro a dezembro o aumento variou de $0,39^{\circ} \mathrm{C} /$ década (média de dezembro) a $0,83^{\circ} \mathrm{C} /$ década (mínimo absoluto de dezembro). 
Janeiro

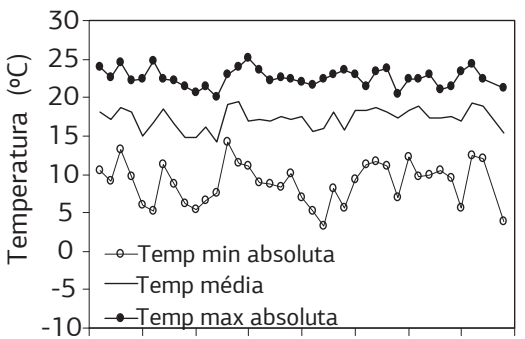

197019751980198519901995200020052010
Fevereiro

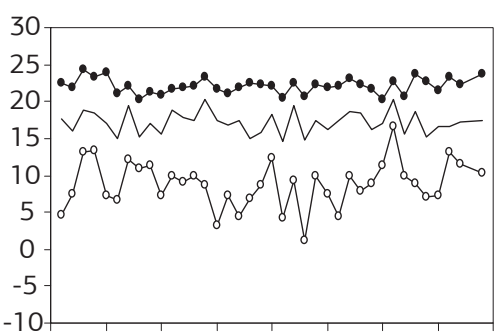

$\begin{array}{llllllll}1970 & 1975 & 1980 & 1985 & 1990 & 1995 & 2000 & 2005 \quad 2010\end{array}$

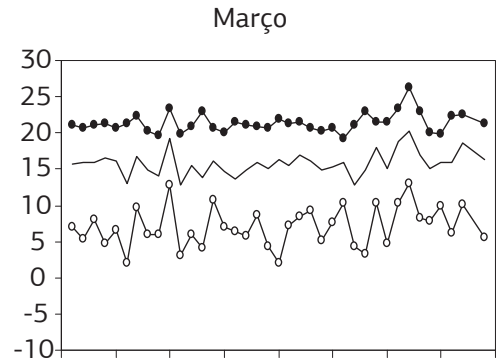

$19701975 \quad 1980198519901995200020052010$

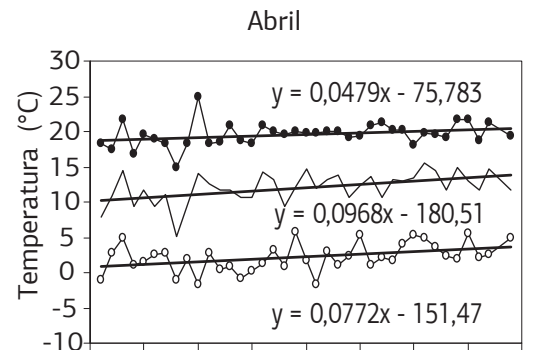

$197019751980198519901995 \quad 200020052010$

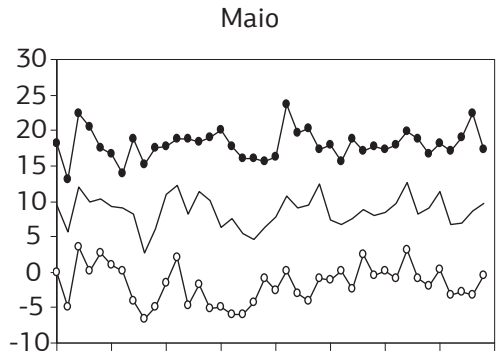

$\begin{array}{llllllll}1970 & 1975 \quad 1980 & 1985 & 1990 & 1995 & 2000 & 2005 & 2010\end{array}$

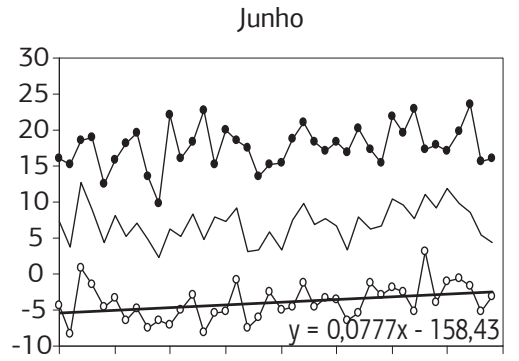

$\begin{array}{lllllllll}1970 & 1975 & 1980 & 1985 & 1990 & 1995 & 2000 & 2005 & 2010\end{array}$
Julho

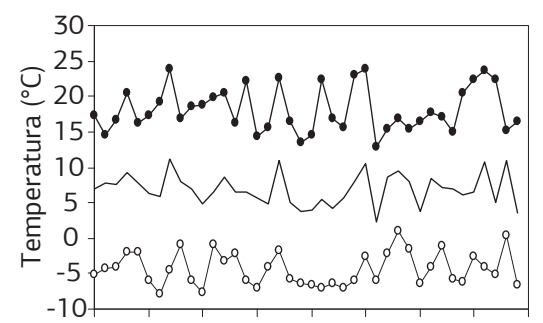

$19701975 \quad 1980198519901995200020052010$

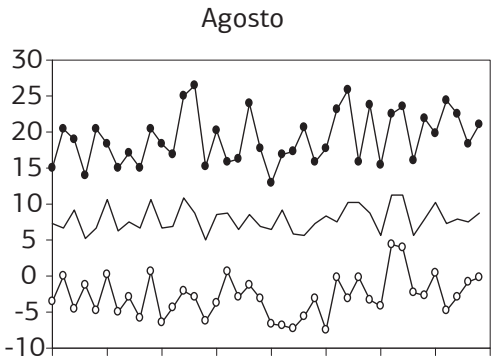

$19701975 \quad 1980198519901995 \quad 200020052010$
Setembro

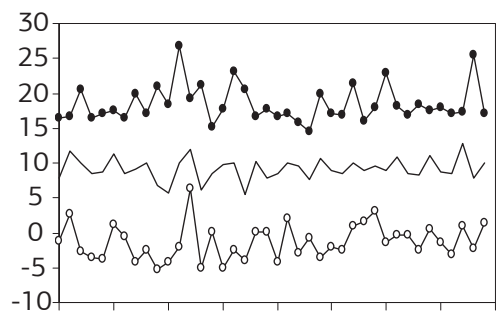

$19701975 \quad 1980198519901995 \quad 2000 \quad 20052010$

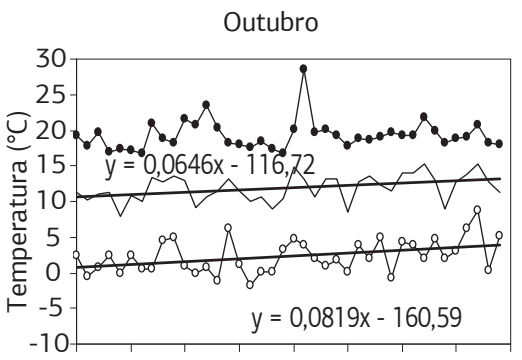

197019751980198519901995200020052010

Anos

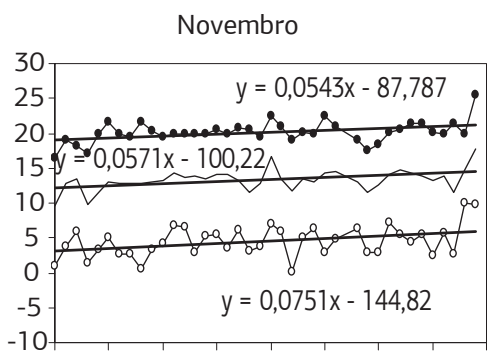

$19701975 \quad 1980198519901995200020052010$

Anos

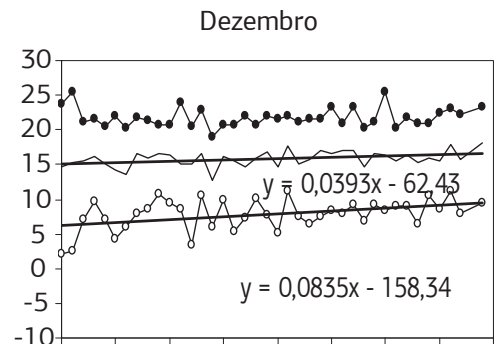

$19701975 \quad 1980198519901995200020052010$

Anos

Figura 3. Mínima, média e máxima absoluta mensal de temperatura mínima de relva média $\left({ }^{\circ} \mathrm{C}\right)$, em Santa Maria, RS, durante o período entre 1970-2009. As equaçôes de regressão com as linhas de tendências estão representadas nas variáveis e meses em que a tendência foi significativa pelo teste de Mann-Kendall a 5\% de probabilidade e o intervalo de confiança do coeficiente angular da regressáo linear simples não incluiu o valor zero. 
Tabela 5. Ano de início da tendência de alteração na temperatura mínima de relva estimados pelo teste de Mann-Kendall e pelo teste de Pettitt

\begin{tabular}{|c|c|c|}
\hline Variável & $\begin{array}{c}\text { Teste de } \\
\text { Mann-Kendall }\end{array}$ & Teste de Pettitt \\
\hline $\begin{array}{l}\text { Mínima absoluta de Tmr - } \\
\text { abril }\end{array}$ & 1998 & 1991 \\
\hline Média de Tmr - abril & 1986 & 1985 \\
\hline $\begin{array}{l}\text { Máxima absoluta de Tmr - } \\
\text { abril }\end{array}$ & 1985 & 1985 \\
\hline $\begin{array}{l}\text { Mínima absoluta de Tmr - } \\
\text { junho }\end{array}$ & 1998 & $1997^{\text {ns }}$ \\
\hline $\begin{array}{l}\text { Mínima absoluta de Tmr - } \\
\text { outubro }\end{array}$ & 1998 & 1988 \\
\hline Média de Tmr - outubro & 1996 & 1989 \\
\hline $\begin{array}{l}\text { Mínima absoluta de Tmr - } \\
\text { novembro }\end{array}$ & 1980 & $1980^{\text {ns }}$ \\
\hline Média de Tmr - novembro & 1980 & $1979^{\text {ns }}$ \\
\hline $\begin{array}{l}\text { Máxima absoluta de Tmr - } \\
\text { novembro }\end{array}$ & 1984 & $1984^{\text {ns }}$ \\
\hline $\begin{array}{l}\text { Temperatura mínima } \\
\text { absoluta - dezembro }\end{array}$ & 1979 & $1977^{\text {ns }}$ \\
\hline Média de Tmr - dezembro & 1989 & $1987^{\text {ns }}$ \\
\hline
\end{tabular}

Apesar de estes valores serem superiores aos encontrados para diversos locais do Estado do Rio Grande do Sul por Sansigolo e Kayano (2010) $\left(0,15\right.$ a $0,19{ }^{\circ} \mathrm{C} /$ década $)$ e aos observados para diversos locais do Estado de São Paulo por BLAIN et al. (2009) $\left(0,10\right.$ a $0,32^{\circ} \mathrm{C} /$ década), a tendência geral de aumento na Tmr em alguns meses (Figura 3) concorda com resultados de aumento na temperatura mínima do abrigo meteorológico constantes no quarto relatório do IPCC (2007) e relatados para diferentes locais do Globo como: Filipinas (Peng et al., 2004), China (TAO et al., 2006) e Brasil em Campinas, SP (Blain et al., 2009) e na região do Planalto Meridionalriograndense (KuinchtNer et al., 2007).

Com relação ao início da tendência nas séries históricas, no fim da década de 1970 iniciou-se uma tendência crescente no aumento da mínima absoluta da Tmr em dezembro segundo o teste de Mann - Kendall; pelo teste de Pettitt não foi identificada uma mudança brusca significativa na série (Tabela 5). Na década de 80 houve início do aumento nas mínimas absoluta, média e máxima absoluta da Tmr de novembro e da média absoluta da Tmr de dezembro pelo teste de Mann - Kendall, mas pelo teste de Pettitt não foi identificada uma mudança brusca significativa na série. Para a média e a máxima absoluta da Tmr de abril pelo teste de Mann - Kendall o início crescente da tendência foi, respectivamente, em 1986 e 1985 e o teste de Pettitt indicou uma mudança brusca significativa ocorrendo em 1985 para estas duas séries de temperaturas (Tabela 5). A mínima absoluta da Tmr de abril, junho e outubro indicou início da tendência na década de 90 e pelo teste de Pettitt a mudança brusca significativa ocorreu em 1991, 1997 e 1988 respectivamente. O teste de Mann - Kendall indicou que há tendência crescente na média absoluta da Tmr em outubro com início da mudança em 1996 e o teste de Pettitt mostrou uma mudança brusca em 1989 (Tabela 5). Estes resultados indicam que a maioria dos aumentos na Tmr iniciou-se na década de 80 .

$\mathrm{Na}$ agricultura de regiôes subtropicais como é o caso do presente estudo, o aumento na Tmr durante o inverno tem efeitos negativos na acumulação de horas de frio para quebra de dormência de frutíferas caducifólias, como o pessegueiro e a macieira, e na taxa de sobrevivência de insetos pragas de culturas de verão. Um aumento na Tmr na primavera e principalmente no verão, aumenta a respiração do tecido vegetal no período noturno, o que pode ter impacto negativo reduzindo a fotossíntese liquida e a produtividade das culturas. Assim, apesar de não haver tendência de aumento da Tmr em sete meses (Figura 3), é preocupante que em outros cinco meses houve tendência de aumento. Por outro lado, um aumento da Tmr, principalmente em outubro, pode ter benefícios para culturas de inverno, como trigo, por estarem no início da fase reprodutiva neste mês e na antecipaçáo da semeadura de culturas de verão. É possível que parte da tendência de aumento na Tmr no período 1970-2009 possa ser devido a uma oscilação de baixa frequência em nível decadal (KaYano e SANSigolo, 2009), mas náo pode ser descartada a possibilidade destes aumentos serem sinal do Aquecimento Global (Ipcc, 2007). Portanto, é prudente que o setor agrícola do Rio Grande do Sul esteja alerta a possíveis alteraçôes de elementos climáticos, como a temperatura mínima do ar, no futuro e assim tome medidas mitigativas e de adaptação de médio e longo prazo, pois os riscos envolvidos na cadeia produtiva das culturas agrícolas, que já são elevados, podem aumentar para as futuras gerações.

\section{CONCLUSÂO}

A climatologia da temperatura mínima de relva em Santa Maria caracteriza-se por elevada variabilidade dentro e entre os meses. A média mensal varia de $6,9^{\circ} \mathrm{C}$ em julho a $17,3^{\circ} \mathrm{C}$ em janeiro, com mínima absoluta de $-8,4^{\circ} \mathrm{C}$ em junho e máxima absoluta de $28,6^{\circ} \mathrm{C}$ em outubro.

Há sinal do ENOS sobre a temperatura mínima de relva nos meses de outono, inverno e primavera de modo que esta é maior em anos de El Niño, menor em anos de La Nińa e intermediária em anos Neutros.

Há aumento na temperatura mínima de relva no período de 1970-2009 em de abril, junho, outubro, novembro e dezembro, com maior elevação no valor médio de abril $\left(0,97^{\circ} \mathrm{C} /\right.$ década $)$ e menor no valor médio de dezembro $\left(0,39^{\circ} \mathrm{C} /\right.$ década). $\mathrm{O}$ aumento iniciou principalmente na década de 80 . 


\section{REFERÊNCIAS}

BACK, A.J. Aplicação de análise estatística para identificação de tendências climáticas. Pesquisa Agropecuária Brasileira, v.36, p.717-726, 2001.

BASISTHA, A.; ARYA, D.S.; GOEL, N.K. Analysis of historical changes in rainfall in the Indian Himalayas. International Journal of Climatology, v.29, p.555-572, 2009.

BERLATO, M.A.; FONTANA, D.C. El Niño e La Niña: impactos no clima, na vegetaçáo e na agricultura do Rio Grande do Sul; aplicaçóes de previsóes climáticas na agricultura. Porto Alegre: UFRGS, 2003. 110p.

BLAIN, G.C.; PICOLI, M.C.A.; LULU, J. Análise estatística das tendências de elevação nas séries anuais de temperatura mínima do ar no Estado de São Paulo. Bragantia, v.68, p.807-815, 2009.

BOOTSMA, A. Estimating grass minimum temperatures from screen minimum values and other climatological parameters. Agricultural Meteorology, v.16, p.103-113, 1976.

BURIOL, G.A.; ESTEFANEL, V.; MATZENAUER, R.; CARNGNELUTTI FILHO, A.; TAZZO, I.F; GAZOLA, M. Homogeneidade da radiação solar global nas estaçóes agrometeorológicas da Fundação Estadual de Pesquisa Agropecuária do Estado do Rio Grande do Sul, Brasil. Pesquisa Agropecuária Gaúcha, v.12, p.65-72, 2006.

CANE, M. A. Understanding and predicting the world's climate system. In: Impacts of El Nino and climate variability on Agriculture. Madison: ASA Special Publication, 2001, p.1-20.

CUNHA, G.R. El Niño Oscilaçâo Sul e perspectivas climáticas aplicadas no manejo de culturas no sul do Brasil. Revista Brasileira de Agrometeorologia, v.7, p.277-284, 1999.

ESTEFANEL, V.; SCHNEIDER, F.M.; BERLATO, M.A.; BURIOL, G.A.; HELDWEIN, A. B. Insolação e radiação solar na regiáo de Santa Maria, RS: I-Estimativa da radiaçáo solar global incidente a partir dos dados de insolação. Revista do Centro de Ciências Rurais, v.20, p.203218,1990 .

FERREIRA, C.C.; FONTANA, D.C.; BERLATO, M.A. Relação entre a temperatura mínima do ar medida no abrigo meteorológico e na relva no Estado do Rio Grande do Sul. Revista Brasileira de Agrometeorologia, v.14, p.53-63, 2006.

FONTANA, D.C.; BERLATO, M.A. Influência do El Niño Oscilação Sul sobre a precipitaçáo do Estado do Rio Grande do Sul. Revista Brasileira de Agrometeorologia, v.5, p.127-132, 1997.

GRIMM, A.; FERRAZ, S.E.T.; GOMES, J. Precipitation anomalies in southern Brazil associated with El Niño and La Niña events. Journal of Climate, v.11, p.2863-2880, 1998.

GRIMM, A.M.; BARROS, V.R.; DOYLE, M.E. Climate variability in Southern South America associated with El Niño and La Niña events. Journal of Climate, v.13, p.35-58, 2000.

HAMED, K.H.; RAO, A.R. A modified Mann-kendall trend test for autocorrelated data. Journal of Hydrology, v.204, p.182-196, 1998.

HELDWEIN, A.B.; ESTEFANEL, V.; MANFRON, P.A.; SACCOL, A.V.; BURIOL, G.A.; SCHNEIDER, F.M. Análise das temperaturas mínimas do ar registradas em Santa Maria, RS. I- Estimativa das temperaturas mínimas do ar a $5 \mathrm{~cm}$ da superfície do solo relvado e do solo desnudo. Revista do Centro de Ciências Rurais, v.18, p.3-14, 1988.
HELDWEIN, A.B.; STRECK, N.A.; BURIOL, G.A.; SANDRI, M.A.; TRENTIN, G.; SPOHR, R.B.; SILVA, J.C.; ALBERTO, C.M.; FARIA, N.S. Frequência de ocorrência de ventos fortes em Santa Maria, RS. Revista Brasileira de Agrometeorologia, v.11, p.285-291, 2003.

IPCC [Intergovernmental Panel on Climate Change]. Climate change 2007: The physical Science Basis - Contribution of Working Group I to the Fourth assessment report of the Intergovernmental Panel on Climate Change. United Kingdom and New York: Cambridge University, 2007. 989p.

KAYANO, M.T.; SANSIGOLO, C. Interannual to decadal variations of precipitation and daily maximum and daily minimum temperatures. Theoretical and Applied Climatology, v.97, p.81-90, 2009.

KUINCHTNER, A.; BURIOL, G.A. Clima do Estado do Rio Grande do Sul segundo a classificação climática de Köppen e Thornthwaite. Disciplinarum Scientia, v.2, p.171-182, 2001.

KUINCHTNER, A.; SIMÓES, J.C.; BURIOL, G.A. Variabilidade da temperatura do ar na regiáo do Planalto Meridional-riograndense em função do aquecimento global. Revista Brasileira de Agrometeorologia, v.15, p.232-249, 2007.

NOAA [National Oceanic And Atmospheric Administration]. ENSO: Cold and warm episodes by season. Washington: NOAA, 2010. Disponível: http://www.cpc.noaa.gov/products/analysis_monitoring/ insostuff/ensoyears.shtml. Acesso em: 30 de mar. 2010.

PAULA, G.M.; STRECK, N.A.; ZANON, A.J.; ELTZ, F.L.F.; HELDWEIN, A.B.; FERRAZ, S.E.T. Influência do fenômeno El Niño na erosividade das chuvas na regiáo de Santa Maria, RS. Revista Brasileira de Ciência do Solo, v.34, p.1315-1323, 2010.

PENG, S.; HUANG, J.; SHEEHY, J.E.; LAZA, R.C.; VISPERAS, R.M.; ZHONG, X.; CENTENO, G.S.; KHUSH, G.S.; CASSMAN, K.G. Rice yields decline with higher night temperatures from global warming. Proceedings of the National Academy of Sciences of the USA, v.101, p.9971-9975, 2004.

SANSIGOLO, C.A.; KAYANO, M.T. Trends of seasonal maximum and minimum temperatures and precipitation in Southern Brazil for the 1913-2006 period. Theoretical and Applied Climatology, v.101, p.209216, 2010.

SHAHID, S. Rainfall variability and the trends of wet and dry periods in Bangaldesh. International Journal of Climatology, v.29, p.573-587, 2009.

SOUZA, M.A.; GEORGEN, R.; FERRAZ, S.E.T. Previsão de precipitaçáo e temperatura em Santa Maria por meio de um modelo estatístico. Ciência e Natura, v.31, p.49-64, 2009.

STRECK, N.A.; ROSA, H.T.; WALTER, L.C.; BOSCO, L.C.; LAGO, I.; HELDWEIN, A.B. O fenômeno El Niño Oscilação Sul e a variabilidade interanual da evaporaçáo do tanque Classe A e da umidade relativa do ar em Santa Maria, RS. Ciência Rural, v.38, p.1452-1455, 2008.

STRECK, N.A.; BURIOL, G.A.; HELDWEIN, A.B.; GABRIEL, L.F.; PAULA, G.M. Associação da variabilidade da precipitação pluvial em Santa Maria com a Oscilaçáo Decadal do Pacífico. Pesquisa Agropecuária Brasileira, v.44, p.1553-1561, 2009.

TAO, F.; YOKOZAWA, M.; XU, Y.; HAYASHI, Y.; ZHANG, Z. Climate changes and trends in phenology and yields of field crops in China, 1981-2000. Agricultural and Forest Meteorology, v.138, p.8292., 2006. 